\title{
ABSORÇÃO DE NUTRIENTES E ALTERAÇÕES QUÍMICAS EM LATOSSOLOS CULTIVADOS COM PLANTAS DE COBERTURA EM ROTAÇÃO COM SOJA E MILHO(1)
}

\author{
Wander Luis Barbosa Borges ${ }^{(2)}$, Rogério Soares de Freitas ${ }^{(2)}$, Gustavo Pavan Mateus ${ }^{(3)}$, \\ Marco Eustáquio de Sá(4) \& Marlene Cristina Alves ${ }^{(5)}$
}

\begin{abstract}
RESUMO
Os efeitos promovidos pelas plantas de cobertura nos atributos químicos do solo são bastante variáveis, dependendo de fatores como espécie utilizada, manejo dado à biomassa, época de plantio e corte das plantas, tempo de permanência dos resíduos no solo, condições locais e interação entre esses fatores. Este trabalho foi realizado com o objetivo de avaliar a absorção de nutrientes por cinco plantas de cobertura, que foram utilizadas para produção de grãos, sementes e forragem, em diferentes quantidades de sementes por hectare e pela vegetação espontânea, bem como para o efeito sobre as propriedades químicas de dois Latossolos, cultivadas em rotação com as culturas da soja e do milho. Os experimentos foram instalados em Votuporanga, SP, e Selvíria, MS, em março de 2008, após o preparo convencional do solo. $O$ delineamento experimental utilizado foi o de blocos casualizados com quatro repeticões, utilizando as seguintes plantas de cobertura em diferentes quantidades de sementes por hectare que constituíram os tratamentos: sorgo granífero: 6,7 e $8 \mathrm{~kg} \mathrm{ha}^{-1}$; milheto: 10,15 e $20 \mathrm{~kg} \mathrm{ha}^{-1}$; capimsudão: 12 , 15 e $18 \mathrm{~kg} \mathrm{ha}^{-1}$; híbrido de sorgo com capim-sudão: 8,9 e $10 \mathrm{~kg} \mathrm{ha}^{-1}$; e Urochloa ruziziensis: 8,12 e $16 \mathrm{~kg} \mathrm{ha}^{-1}$. Também se utilizou um tratamento-controle com vegetação espontânea. Após o manejo das coberturas, no primeiro ano de estudo, foi semeada a soja e, no segundo ano, semeou-se o milho, ambos em sistema
\end{abstract}

(1) Parte da Tese de Doutorado do primeiro autor apresentada ao Programa de Pós-Graduação em Agronomia - Sistemas de Produção, da Universidade Estadual Paulista - UNESP. Recebido para publicação em 29 de outubro de 2012 e aprovado em 17 de setembro de 2013.

(2) Pesquisador Científico do Polo Regional de Desenvolvimento Tecnológicos dos Agronegócios do Noroeste Paulista, Agência Paulista de Tecnologia dos Agronegócios, APTA. Rod. Péricles Belini, km 121. Caixa Postal 61. CEP 15500-970 Votuporanga (SP). E-mail: wanderborges@apta.sp.gov.br, freitas@apta.sp.gov.br

(3) Pesquisador Científico do Polo Regional de Desenvolvimento Tecnológicos dos Agronegócios do Extremo Oeste, Agência Paulista de Tecnologia dos Agronegócios, APTA. Estrada Vicinal Nemezião de Souza Pereira, km 06. Caixa Postal 67. CEP 16900-970 Andradina (SP). E-mail: gpmateus@apta.sp.gov.br

(4) Professor Titular, Departamento de Fitotecnia, Tecnologia de Alimentos e Sócio-Economia, Universidade Estadual Paulista UNESP. Av. Brasil, 56. CEP 15385-000 Ilha Solteira (SP). E-mail: mesa@agr.feis.unesp.br

(5) Professor Titular, Departamento de Fitossanidade, Engenharia Rural e Solos, UNESP. Bolsista de Produtividade do CNPq. Email: mcalves@agr.feis.unesp.br 
de semeadura direta. Avaliaram-se a produtividade de matéria seca das diferentes coberturas, a absorção de nutrientes pelas coberturas e as alterações químicas no solo. Constatou-se que em solos argilosos, com elevado teor de alumínio no solo, como em Selvíria, o capim-sudão, com $18 \mathrm{~kg} \mathrm{ha}^{-1}$ de sementes, e o sorgo granífero, com $6 \mathrm{~kg} \mathrm{ha}^{-1}$, em associação a calagem, contribuem para redução do teor de alumínio e da acidez potencial e para elevação da saturação por bases. As diferentes quantidades de sementes de cada planta de cobertura não influenciaram a produtividade de matéria seca da mesma planta de cobertura, mas interferiram na absorção de nitrogênio do híbrido de sorgo com capim-sudão, com $10 \mathrm{~kg} \mathrm{ha}^{-1} \mathrm{de}$ sementes, apresentando menor absorção que com $8 \mathrm{~kg} \mathrm{ha}^{-1}$ de sementes, e também no teor de matéria orgânica no solo, com o capim-sudão, com $15 \mathrm{~kg} \mathrm{ha}^{-1}$ de sementes, propiciando maior teor que o de $18 \mathrm{~kg} \mathrm{ha}^{-1}$ de sementes.

Termos de indexação: Glycine Max, Zea mays, ciclagem de nutrientes, manejo sustentável do solo.

\section{SUMMARY: NUTRIENT UPTAKE AND CHEMICAL CHANGES IN OXISOLS PLANTED TO COVER CROPS IN ROTATION WITH SOYBEAN $A N D C O R N$}

The effects on soil chemical properties brought about by cover crops vary considerably. This study was conducted to evaluate nutrient uptake by five cover crops used for grain, seed and forage production at different seed densities per hectare, as well as uptake by spontaneous vegetation, and their effect on the chemical properties of two Oxisols when grown in rotation with soybean and corn. The experiments were set up in Votuporanga, SP, Brazil and Selviria, MS, Brazil in March 2008 after conventional soil tillage. A randomized complete block experimental design was used with four replications with the following cover crops at different seed densities: Sorghum bicolor at 6,7 and $8 \mathrm{~kg} \mathrm{ha}^{-1}$; Pennisetum americanum at 10, 15 and

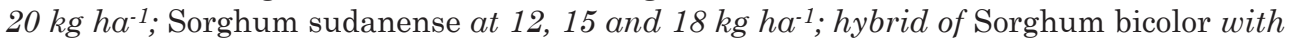
Sorghum sudanense at 8, 9 and $10 \mathrm{~kg} \mathrm{ha}^{-1}$; and Urochloa ruziziensis at 8, 12 and $16 \mathrm{~kg} \mathrm{ha}^{-1}$. We also used a spontaneous vegetation control. After management of the cover crops, in the first year of study, soybean was sown in no-tillage system and, in the second year, corn was sown, also in a no-tillage system. We evaluated the dry matter yield of different cover crops, nutrient uptake by the cover crops, and the chemical changes in the soil. It was found that in clayey soils with high aluminum content, as in Selviria, sudan grass at a seed density of $18 \mathrm{~kg} \mathrm{ha}^{-1}$, and sorghum at a seed density of $6 \mathrm{~kg} \mathrm{ha}^{-1}$, in combination with liming, contributed to reduction of aluminum content and high potential acidity and an increase in base saturation. The different seed densities of each cover crop did not affect the dry matter yield of the cover crop itself, but affected nitrogen uptake of the hybrid Sorghum bicolor with Sorghum sudanense at a seed density of $10 \mathrm{~kg} \mathrm{ha}^{-1}$, with lower uptake than at a seed density of $8 \mathrm{~kg} \mathrm{ha}^{-1}$. Seed density also affected the organic matter content in the soil with sudan grass, with the seed density of $15 \mathrm{~kg} \mathrm{ha}^{-1}$ providing more organic matter content than a seed density of $18 \mathrm{~kg} \mathrm{ha}^{-1}$.

Index terms: Glycine max, Zea mays, nutrient cycling, sustainable soil management.

\section{INTRODUÇÃO}

A implantação de sistemas de manejo conservacionistas, que têm como princípio a manutenção de cobertura vegetal e seus resíduos sobre o solo, tem-se destacado como uma das estratégias eficazes para aumentar a sustentabilidade dos sistemas agrícolas nas regiões tropicais e subtropicais (Caires et al., 2006).

A utilização de culturas na entressafra com o objetivo de cobertura do solo e ciclagem de nutrientes, visando à diversificação da produção agrícola com sustentabilidade (Chaves \& Calegari, 2001), é uma estratégia para melhoria da qualidade ambiental e diminui os efeitos nocivos do monocultivo (Boer et al., 2007).

O uso de plantas de cobertura pode restituir quantidades consideráveis de nutrientes aos cultivos, uma vez que essas plantas absorvem nutrientes das camadas subsuperficiais do solo e os liberam, posteriormente, na camada superficial pela decomposição dos seus resíduos (Duda et al., 2003). No entanto, os efeitos promovidos pelas plantas de cobertura nos atributos químicos do solo são bastante variáveis, dependendo de fatores como espécie utilizada, manejo dado à biomassa, época de plantio e corte das plantas, tempo de permanência dos resíduos no solo, condições locais e interação entre esses fatores (Alcântara et al., 2000). 
Trabuco (2008) citou que de maneira geral não há mudanças significativas nos atributos químicos do solo em rotações de culturas, mesmo em longo período de tempo e com utilização de plantas de cobertura, por período de tempo curto. No entanto, Correia \& Durigan (2008), após dois anos de semeadura direta comparando diversas espécies de gramíneas usadas como plantas de cobertura e vegetação espontânea, observaram alterações nas propriedades químicas do solo, com respostas nas profundidades de amostragem estudadas. Teixeira et al. (2003) destacaram que as gramíneas forrageiras apresentam sistema radicular bastante extenso e em constante renovação, que, associado ao elevado potencial de produção de matéria seca, são capaz de, em pouco tempo, alterar os níveis de matéria orgânica e nutrientes do solo.

Alguns estudos evidenciaram que o acúmulo de matéria orgânica nas camadas superficiais do solo influencia o $\mathrm{pH}$ e os teores de nutrientes, refletindo em alterações nos valores da capacidade de troca catiônica e da saturação por bases do solo. Isso ocorre pela maior retenção de cátions liberados pela decomposição dos resíduos das coberturas nessa camada superficial, além de a matéria orgânica do solo reduzir a lixiviação de nutrientes (Bayer \& Mielniczuk, 1997; Rheinheimer et al., 1998).

Segundo Primavesi et al. (2002), em estudos sobre plantas de cobertura, observou-se que a quantidade de nutrientes acumulados depende da espécie, da fertilidade do solo, do estádio fenológico na dessecação, da relação $\mathrm{C} / \mathrm{N}$, da época de plantio, além das condições climáticas de cada estudo.

Diversos trabalhos avaliando a influência de plantas de cobertura nas propriedades químicas do solo têm sido realizados (Boer et al., 2007; Correia \& Durigan, 2008; Torres \& Pereira, 2008; Torres et al., 2008; Trabuco, 2008; Santos et al., 2012), porém há escassez de estudos envolvendo plantas de cobertura com objetivo de produção de grãos, sementes ou forragem, aliado à produção de fitomassa e ciclagem de nutrientes.

Este trabalho foi realizado com o objetivo de avaliar a absorção de nutrientes por cinco plantas de cobertura, utilizadas para produção de grãos, sementes e forragem, em diferentes quantidades de sementes por hectare e pela vegetação espontânea, bem como o efeito sobre as propriedades químicas de dois Latossolos, cultivados em rotação com as culturas da soja e do milho.

\section{MATERIAL E MÉTODOS}

Os experimentos foram instalados em março de 2008, no Polo Regional de Desenvolvimento Tecnológico dos Agronegócios do Noroeste Paulista APTA, estabelecido no município de Votuporanga, $\mathrm{SP}$, a $20^{\circ} 20^{\prime} \mathrm{S}$ de latitude, $49^{\circ} 58^{\prime} \mathrm{W}$ de longitude e
510 m de altitude, em um Latossolo Vermelho eutrófico de textura arenosa (Prado et al., 1999; Embrapa, 2006), e na Fazenda de Ensino, Pesquisa e Extensão da UNESP, Campus de Ilha Solteira, localizada no município de Selvíria, MS, na Seção de Produção Vegetal, com coordenadas geográficas: latitude $20^{\circ} 25^{\prime} 24^{\prime}$ 'S, longitude $52^{\circ} 21^{\prime} 13^{\prime}$ 'W e altitude média de $335 \mathrm{~m}$, em um Latossolo Vermelho distroférrico típico de textura argilosa (Demattê, 1980; Embrapa, 2006). O clima da região, segundo a classificação de Köppen, é do tipo Aw, definido como tropical úmido com estação chuvosa no verão e seca no inverno, apresentando temperatura média anual de $24,5{ }^{\circ} \mathrm{C}$, precipitação pluvial média anual de $1.232 \mathrm{~mm}$, umidade relativa média anual de $64,8 \%$ e déficit hídrico acentuado nos meses de junho a setembro (Hernandez et al., 1995).

Para o solo de Selvíria, Souza \& Alves (2003) verificaram nas camadas de $0-0,20$ e $0,20-0,40 \mathrm{~m}$ as seguintes quantidades de areia, silte e argila, respectivamente: 325,120 e $555 \mathrm{~g} \mathrm{~kg}^{-1}$; e 290,130 e $580 \mathrm{~g} \mathrm{~kg}^{-1}$.

A amostragem de solo para fins de fertilidade foi realizada na camada de $0-0,20 \mathrm{~m}$, em fevereiro de 2008 , utilizando-se um trado de rosca e retirando-se 10 amostras simples de cada local, de toda a área onde se instalou os ensaios, as quais originaram uma amostra composta de cada local. As amostras foram encaminhadas para análise de fertilidade. Utilizou-se o método proposto por Raij et al. (2001), apresentando os seguintes resultados para Votuporanga e Selvíria, respectivamente: $\mathrm{P}$ (resina): 28 e $8 \mathrm{mg} \mathrm{dm}^{-3}$; MO: 14 e $19 \mathrm{mg} \mathrm{dm}^{-3} ; \mathrm{pH}$ $\left(\mathrm{CaCl}_{2}\right): 5,2$ e 4,$2 ; \mathrm{K}: 3,8$ e $1,0 \mathrm{mmol}_{\mathrm{c}} \mathrm{dm}^{-3} ; \mathrm{Ca}: 16$ e $6 \mathrm{mmol}_{\mathrm{c}} \mathrm{dm}^{-3} ; \mathrm{Mg}$ : 8 e $6 \mathrm{mmol}_{\mathrm{c}} \mathrm{dm}^{-3} ; \mathrm{H}+\mathrm{Al}: 16 \mathrm{e}$ $47 \mathrm{mmol}_{\mathrm{c}} \mathrm{dm}^{-3}$; Al: 0 e $8 \mathrm{mmol}_{\mathrm{c}} \mathrm{dm}^{-3}$; $\mathrm{S}_{-} \mathrm{SO}_{4}: 2$ e $3 \mathrm{mg}$ $\mathrm{dm}^{-3}$; e V: 63 e $22 \%$. Foi realizada calagem em Selvíria para elevação da saturação por bases a $70 \%$, pois no ano seguinte seria introduzida a cultura do milho na área, utilizando-se $3.400 \mathrm{~kg} \mathrm{ha}^{-1}$ de calcário dolomítico, com PRNT de $85 \%$, incorporado com a segunda gradagem.

O solo foi preparado por meio de uma aração (arado de discos), em fevereiro de 2008, e duas gradagens (grade niveladora de discos), uma em fevereiro e outra no início de março.

O delineamento experimental utilizado foi o de blocos casualizados com quatro repetições, utilizandose cinco plantas de cobertura, com três diferentes quantidades de sementes ha-1 de cada planta de cobertura e um tratamento-controle com vegetação espontânea, totalizando 16 tratamentos, distribuídos ao acaso em parcelas de 2,7 m de largura por $10 \mathrm{~m}$ de comprimento cada.

Foram utilizadas como plantas de cobertura: sorgo granífero (Sorghum bicolor (L.) Moench), cultivar DKB 550, com $85 \%$ de germinação e 6 , 7 e $8 \mathrm{~kg} \mathrm{ha}^{-1}$ de sementes; milheto (Pennisetum americanum (L.) Leek), cultivar BN 2, com 60 \% de germinação e 10, 
15 e $20 \mathrm{~kg} \mathrm{ha}^{-1}$ de sementes; capim-sudão (Sorghum sudanense (Piper) Stapf) com valor cultural (VC) de $43,5 \%$, sendo corrigido para $100 \%$, e 12,15 e $18 \mathrm{~kg} \mathrm{ha}^{-1}$ de sementes;; híbrido de sorgo com capim-sudão (Sorghum bicolor (L.) Moench) com Sorghum sudanense (Piper) Stapf), cultivar Cover Crop, com germinação de $74 \%$, sendo acrescidos $10 \%$, e 8,9 e $10 \mathrm{~kg} \mathrm{ha}^{-1}$ de sementes; e Urochloa ruziziensis (Syn. Brachiaria ruziziensis) (cultivar comum), com VC de $50,7 \%$, sendo acrescidos $10 \%$, e 8, 12 e $16 \mathrm{~kg} \mathrm{ha}^{-1} \mathrm{de}$ sementes. As diferentes quantidades de sementes utilizadas foram com base em recomendações dos detentores das sementes e de diferentes trabalhos da literatura.

Os espaçamentos entrelinhas utilizados foram: sorgo granífero: 0,45 m; milheto: 0,225 m; capimsudão: 0,225 m; híbrido de sorgo com capim-sudão: 0,45 m; e Urochloa ruziziensis: 0,225 m.

$\mathrm{O}$ tratamento-controle com vegetação espontânea era composto principalmente por Cenchrus echinatus L. e Digitaria horizontalis Willd, nos dois locais. As parcelas com o tratamento-controle foram deixadas em pousio, após o preparo do solo e depois do cultivo da cultura da soja; no entanto, receberam os mesmos tratos culturais das plantas de cobertura.

As plantas de cobertura foram semeadas em 24/ 03/2008, em Votuporanga, mecanicamente com semeadora de parcelas, e em 26/03/2008, em Selvíria, manualmente, abrindo-se sulcos de plantio com enxadas adaptadas, distribuindo as sementes no sulco e depois tampando o sulco com enxadas adaptadas.

A semeadura das plantas de cobertura foi realizada após a adubação de plantio, feita mecanicamente com semeadoras de grãos em toda a área, inclusive nas parcelas-controle, utilizando-se o fertilizante formulado 08-28-16 nas doses de 170 e $315 \mathrm{~kg} \mathrm{ha}^{-1}$, em Votuporanga e Selvíria, respectivamente.

A adubação de cobertura foi realizada manualmente a lanço, em toda a área, inclusive nas parcelascontrole. Utilizaram-se sulfato de amônio, na dose de $185 \mathrm{~kg} \mathrm{ha}^{-1}$, aos 15 dias após a semeadura, e ureia, na dose de $170 \mathrm{~kg} \mathrm{ha}^{-1}$, aos 30 dias após a semeadura, em Votuporanga; e ureia, na dose de $65 \mathrm{~kg} \mathrm{ha}^{-1}$, e cloreto de potássio, na dose de $35 \mathrm{~kg} \mathrm{ha}^{-1}$, aos 30 dias após a semeadura, em Selvíria.

Por ser a planta de cobertura mais exigente, foi utilizada a cultura do sorgo granífero como referência para as adubações e a calagem, com base nas recomendações de Cantarella et al. (1997).

Foi realizado o corte das panículas do sorgo, milheto e capim-sudão, aos 115, 110 e 125 dias, respectivamente, após a semeadura, simulando-se a colheita de grãos e, ou, sementes. O híbrido de sorgo com o capim-sudão e a Urochloa ruziziensis foram cortados a $0,20 \mathrm{~m}$ do solo e retirados da área, aos 95 e 145 dias após a semeadura, respectivamente, simulando-se ensilagem do híbrido e fenação da Urochloa ruziziensis. No tratamento-controle, deixaram-se as plantas daninhas desenvolverem-se. No final do mês de agosto de 2008, todas as parcelas foram roçadas. No início de novembro, realizou-se a primeira dessecação e 20 dias após, a segunda.

Após as dessecações, foi semeada mecanicamente a cultura da soja, em sistema de semeadura direta, nos dias 28/11/2008 e 03/12/2008, em Selvíria e Votuporanga, respectivamente, utilizando-se o cultivar M-Soy $7908 \mathrm{RR}$, no espaçamento de $0,45 \mathrm{~m}$ com 14 sementes $\mathrm{m}^{-1}$, e $250 \mathrm{~kg} \mathrm{ha}^{-1}$ e $350 \mathrm{~kg} \mathrm{ha}^{-1}$ do adubo formulado 04-20-20, em Votuporanga e Selvíria, respectivamente, conforme Mascarenhas \& Tanaka (1997).

A colheita foi realizada nos dias 08/04/2009 e 16/ 04/2009, em Selvíria e Votuporanga, respectivamente.

No segundo ano de estudo, a semeadura das plantas de cobertura foi realizada nos dias 13/04/2009, em Selvíria, e 18/05/2009, em Votuporanga; fez-se manualmente sobre a palhada de soja cultivada anteriormente, com abertura de sulcos de plantio e distribuição das sementes no sulco; posteriormente, tampou-se o sulco com enxadas adaptadas.

As adubações foram novamente realizadas mecanicamente com semeadoras de grãos em todas as parcelas, utilizando-se o fertilizante formulado 08-28-16 nas doses de 300 e $275 \mathrm{~kg} \mathrm{ha}^{-1}$ em Votuporanga e Selvíria, respectivamente.

O manejo das plantas de cobertura e do tratamento-controle foi o mesmo do ano anterior. As plantas de cobertura foram roçadas no final do mês de julho de 2009, em Selvíria, e em setembro, em Votuporanga.

Em Votuporanga, foi realizada a primeira dessecação das plantas de cobertura em 19/11/2009 e a segunda, em 14/12/2009. Já em Selvíria, realizouse a primeira dessecação em 04/11/2009 e a segunda em 25/11/2009.

Após as dessecações, em Votuporanga, foi realizada a semeadura do milho, em sistema de semeadura direta, em 14/12/2009, utilizando-se o híbrido DKB 350 , com 5,1 sementes $\mathrm{m}^{-1}$, no espaçamento de $0,8 \mathrm{~m}$. $\mathrm{Na}$ adubação de semeadura, utilizaram-se $300 \mathrm{~kg} \mathrm{ha}^{-1}$ do adubo formulado 08-20-20. As adubações de cobertura foram realizadas em 30/12/2009 e em 11/01/2010, utilizando-se sulfato de amônio, na dose de $250 \mathrm{~kg} \mathrm{ha}^{-1}$.

Realizou-se, em Selvíria, após as dessecações, a semeadura do milho em 25/11/2009, utilizando-se o híbrido DKB 350, com 6,0 sementes $\mathrm{m}^{-1}$, no espaçamento de $0,8 \mathrm{~m}$. Na adubação de semeadura, utilizaram-se $320 \mathrm{~kg} \mathrm{ha}^{-1}$ do adubo formulado 08-28-16. As adubações de cobertura foram realizadas em 15/12/2009, utilizando-se $300 \mathrm{~kg} \mathrm{ha}^{-1}$ do adubo formulado 20-00-20. Em 22/12/2009, utilizaram-se $175 \mathrm{~kg} \mathrm{ha}^{-1}$ de sulfato de amônio. As adubações de semeadura e de cobertura da cultura do milho foram realizadas, conforme Raij \& Cantarella (1997). 
Fizeram-se todos os tratamentos fitossanitários necessários para o desenvolvimento adequado das culturas da soja e do milho.

Após a colheita do milho, foram retiradas duas amostras simples de solo por parcela, utilizando-se um trado de rosca, na profundidade de 0-0,20 m. Essas foram homogenizadas em uma amostra composta para posterior análise química de fertilidade do solo.

A extração de $\mathrm{Ca}, \mathrm{Mg}, \mathrm{Ke}$ P foi realizada utilizando resina trocadora de íons; a acidez potencial $(\mathrm{H}+\mathrm{Al})$ foi determinada por titulometria, usando solução de acetato de cálcio $0,5 \mathrm{~mol} \mathrm{~L}^{-1}$ a $\mathrm{pH} 7,0$ para sua extração. $\mathrm{O} \mathrm{pH}$ foi determinado em solução $0,01 \mathrm{~mol} \mathrm{~L}^{-1}$ de $\mathrm{CaCl}_{2} \cdot 2 \mathrm{H}_{2} \mathrm{O}$, e o teor de matéria orgânica (MO), pela combustão úmida com dicromato de potássio, segundo Raij \& Quaggio (1983).

As avaliações de fitomassa das coberturas foram realizadas em 2008 e 2009, no momento da colheita de grãos (sorgo), da colheita de sementes (milheto, capim-sudão e tratamento-padrão) e do corte (híbrido de sorgo x capim-sudão e Urochloa ruziziensis), retirando-se duas amostras de $0,5 \times 0,5 \mathrm{~m}$ por parcela, as quais foram acondicionadas em sacos de papel e levadas para secagem em estufa termoelétrica regulada a $65-70{ }^{\circ} \mathrm{C}$ por $72 \mathrm{~h}$.

No florescimento pleno das coberturas, foram retiradas duas amostras de $0,5 \times 0,5 \mathrm{~m}$ por parcela da parte aérea das plantas de cobertura e do tratamento-padrão. Após a secagem em estufa de ventilação forçada regulada a $65-70{ }^{\circ} \mathrm{C}$ por $72 \mathrm{~h}$, as amostras foram encaminhadas para análise de teores de macronutrientes. Os valores obtidos nessa análise foram utilizados para o cálculo do acúmulo de nutrientes ha $\mathrm{a}^{-1}$, multiplicando-se esses valores pela quantidade de matéria seca produzida ha ${ }^{-1}$ no momento do corte/colheita das plantas de cobertura.

Os dados climáticos de precipitação pluvial ( $\mathrm{mm})$ e temperatura média mensal $\left({ }^{\circ} \mathrm{C}\right)$, em Votuporanga e Ilha Solteira, no período estudado, entre março de 2008 e abril de 2010, estão apresentados na figura 1, respectivamente.

Os dados foram submetidos ao teste $\mathrm{F}$ e realizado o teste de Tukey $(p<0,05)$, para comparação das médias, com o uso do programa computacional ESTAT, desenvolvido pelo Departamento de Ciências Exatas da FCAV/UNESP/Jaboticabal (Estat, 1997).

\section{RESULTADOS E DISCUSSÃO}

O experimento caracterizou-se pela fase inicial de implantação do sistema de semeadura direta, com preparo inicial do sistema por meio de semeadura convencional.

As diferentes quantidades de sementes, de cada planta de cobertura, não influenciaram a produtividade de matéria seca da mesma planta de cobertura, durante os dois anos de estudo, nos dois locais (Quadro 1), mas influenciaram a absorção de $\mathrm{N}$ do híbrido de sorgo com capim-sudão em Votuporanga, quando foram utilizados $10 \mathrm{~kg} \mathrm{ha}^{-1}$ de sementes, apresentando menor absorção que $8 \mathrm{~kg} \mathrm{ha}^{-1}$ de sementes (Quadro 2).

Em Votuporanga, constatou-se que a vegetação espontânea presente no tratamento-controle, associada às adubações de semeadura realizadas, propiciou o maior teor de K no solo (Quadro 3), refletindo a maior absorção desse nutriente, em $\mathrm{g} \mathrm{kg}^{-1}$ de matéria seca, entre as coberturas (Quadro 2), fato também verificado por Torres \& Pereira (2008).

Enfatiza-se que as adubações foram realizadas em todas as parcelas e que a quantidade de sementes de $9 \mathrm{~kg} \mathrm{ha}^{-1}$ do híbrido de sorgo com capim-sudão produziu 7.559 e $4.284 \mathrm{~kg} \mathrm{ha}^{-1}$ de matéria seca, no primeiro e no segundo ano, respectivamente (Quadro 1), e teve a parte aérea retirada da área, extraindo-se $147 \mathrm{~kg} \mathrm{ha}^{-1}$ de K da área no segundo ano de estudo (Figura 2), o que propiciou o menor teor de K no solo (Quadro 3). Já a vegetação espontânea, presente no tratamentocontrole, acumulou $96 \mathrm{~kg} \mathrm{ha}^{-1}$ de K (Figura 2), superior aos valores encontrados por Silva et al. (2006), 51,5 kg ha-1 de K, e não foi retirada da área.

Em Selvíria, verificou-se que o tratamento-controle propiciou o menor teor de Ca (Quadro 3), corroborando com Fabian (2009), maior teor de Al, menor valor de

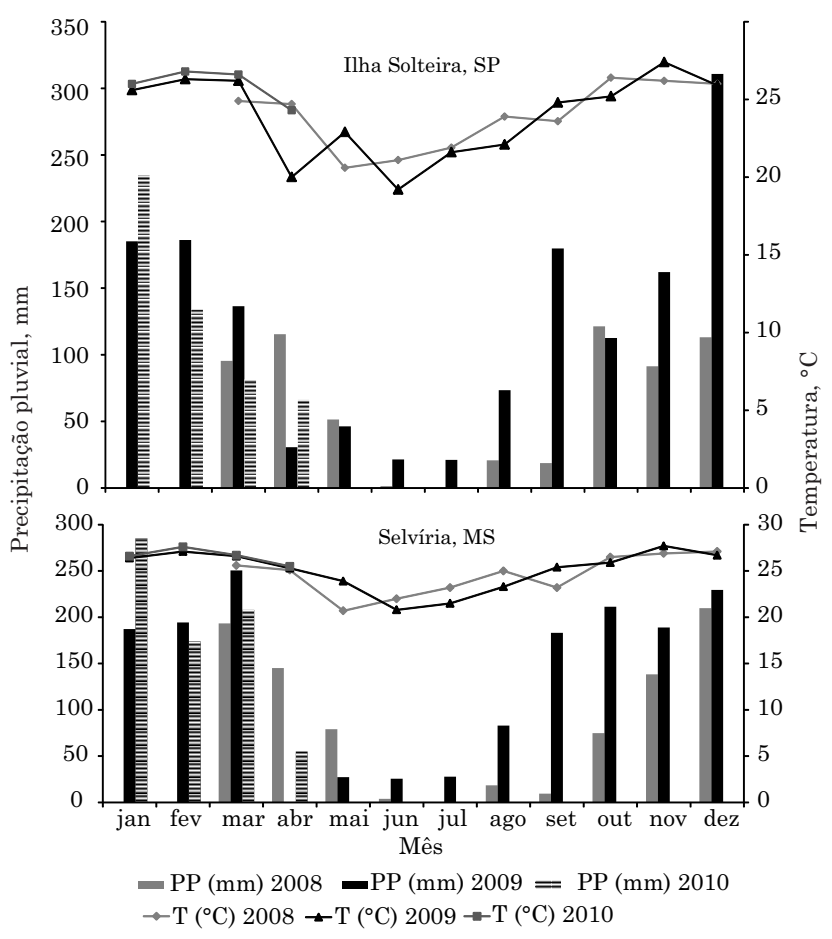

Figura 1. Dados de precipitação pluvial (PP) e temperatura média (T), em Votuporanga, SP e em Ilha Solteira, SP, localizada a $13,9 \mathrm{~km}$ de Selvíria, MS, no período estudado, março de 2008 a abril de 2010. Fonte: Ciiagro (2012). 
Quadro 1. Produtividade de matéria seca da parte aérea das plantas de cobertura e do tratamento-controle no momento do corte/colheita nas duas localidades avaliadas

\begin{tabular}{|c|c|c|c|c|c|}
\hline \multirow{2}{*}{ Cobertura } & \multirow{2}{*}{ Quantidade de semente } & Votuporanga & Selvíria & Votuporanga & Selvíria \\
\hline & & \multicolumn{2}{|c|}{2008} & \multicolumn{2}{|c|}{2009} \\
\hline Sorgo & 6 & $13.997 \mathrm{bcd}$ & $11.932 \mathrm{abc}$ & $7.471 \mathrm{de}$ & $17.273 \mathrm{abc}$ \\
\hline Sorgo & 7 & $16.155 \mathrm{bc}$ & $12.557 \mathrm{ab}$ & $6.938 \mathrm{de}$ & $15.615 \mathrm{abc}$ \\
\hline Sorgo & 8 & $15.260 \mathrm{bcd}$ & $11.918 \mathrm{abc}$ & $7.398 \mathrm{de}$ & $15.663 \mathrm{abc}$ \\
\hline Milheto & 10 & $7.398 \mathrm{efg}$ & 6.283 cde & 7.931 cde & $10.366 \mathrm{~cd}$ \\
\hline Milheto & 15 & $6.310 \mathrm{fg}$ & 6.188 cde & 8.675 cde & $11.253 \mathrm{bcd}$ \\
\hline Milheto & 20 & $7.393 \mathrm{efg}$ & $5.773 \mathrm{de}$ & 8.456 cde & $9.921 \mathrm{~cd}$ \\
\hline Capim-sudão & 12 & 12.596 cde & 6.896 bcde & $16.428 \mathrm{a}$ & $17.138 \mathrm{abc}$ \\
\hline Capim-sudão & 15 & 12.049 cdef & 6.824 bcde & $16.884 \mathrm{a}$ & $24.403 \mathrm{a}$ \\
\hline Capim-sudão & 18 & 11.150 cdef & 6.654 cde & $15.141 \mathrm{ab}$ & $22.898 \mathrm{a}$ \\
\hline Híbrido & 8 & $19.811 \mathrm{ab}$ & $14.774 \mathrm{a}$ & $13.721 \mathrm{abc}$ & $21.872 \mathrm{ab}$ \\
\hline Híbrido & 9 & $23.773 \mathrm{a}$ & $13.322 \mathrm{a}$ & $9.902 \mathrm{bcd}$ & $25.067 \mathrm{a}$ \\
\hline Híbrido & 10 & $23.041 \mathrm{a}$ & $15.422 \mathrm{a}$ & $10.822 \mathrm{abcd}$ & $22.421 \mathrm{ab}$ \\
\hline U. ruziziensis & 8 & $10.814 \mathrm{cdef}$ & $11.050 \mathrm{abcd}$ & 8.446 cde & $16.446 \mathrm{abc}$ \\
\hline U. ruziziensis & 12 & 10.194 cdef & $11.266 \mathrm{abcd}$ & $9.141 \mathrm{bcd}$ & $19.084 \mathrm{abc}$ \\
\hline U. ruziziensis & 16 & 9.399 def & $9.806 \mathrm{abcd}$ & 8.757 cde & $17.725 \mathrm{abc}$ \\
\hline Controle & - & $2.490 \mathrm{~g}$ & $3.400 \mathrm{e}$ & $2.756 \mathrm{e}$ & $3.046 \mathrm{~d}$ \\
\hline DMS & & 6.081 & 5.884 & 6.098 & 1.1376 \\
\hline CV (\%) & & 18,81 & 23,84 & 23,96 & 26,28 \\
\hline
\end{tabular}

Médias seguidas de mesma letra não diferem entre si pelo teste de Tukey a $5 \%$.

saturação por bases e maior acidez potencial $(\mathrm{H}+\mathrm{Al})$. Entretanto, o capim-sudão, com $18 \mathrm{~kg} \mathrm{ha}^{-1}$ de sementes, e o sorgo granífero, com $6 \mathrm{~kg} \mathrm{ha}^{-1}$ de sementes, propiciaram menores teores de $\mathrm{Al}$, menor acidez potencial e maior saturação por bases, constatandose que em solos argilosos, com elevado teor de $\mathrm{Al}$ no solo, como em Selvíria, essas coberturas, em associação com a calagem, podem contribuir para redução do teor de $\mathrm{Al}$ e da acidez potencial e elevação da saturação por bases.

O teor de matéria orgânica no solo, em Selvíria, também foi influenciado pelas diferentes quantidades de sementes; o capim-sudão com $15 \mathrm{~kg} \mathrm{ha}^{-1}$ de sementes propiciou maior teor que $18 \mathrm{~kg} \mathrm{ha}^{-1} \mathrm{de}$ sementes (Quadro 3).

A absorção de $\mathrm{N}$ pelos três diferentes gastos de sementes do sorgo granífero e do milheto, nos dois locais (Quadro 2), foi superior às encontradas por Trabuco (2008), 11 e $16 \mathrm{~g} \mathrm{~kg}^{-1}$ de $\mathrm{N}$ para o sorgo granífero e para o milheto (cultivar $\mathrm{BN} 2$ ), respectivamente.

$\mathrm{O}$ acúmulo de $\mathrm{N}$ pela vegetação espontânea, presente no tratamento-controle, nos dois locais (Figura 2), foi superior ao encontrado por Aita et al. (2001), 20,5 kg ha-1, em $1190 \mathrm{~kg} \mathrm{ha}^{-1}$ de matéria seca, e por Torres et al. (2005), que constataram 46,6 e $57,2 \mathrm{~kg} \mathrm{ha}^{-1}$ de N, com 2.100 e $3.800 \mathrm{~kg} \mathrm{ha}^{-1}$ de matéria seca, no primeiro e no segundo ano de estudo, respectivamente. Em relação ao sorgo granífero, as três diferentes quantidades de sementes, nos dois locais, também propiciaram maior acúmulo de $\mathrm{N}$, superior ao encontrado por Torres et al. (2005), 84,1 e $45,0 \mathrm{~kg} \mathrm{ha}^{-1}$ de $\mathrm{N}$, com 7.100 e $4.000 \mathrm{~kg} \mathrm{ha}^{-1}$ de biomassa seca, no primeiro e no segundo ano de estudo, respectivamente.

As quantidades de $\mathrm{P}$ acumuladas pelas três diferentes quantidades de sementes do milheto, no florescimento, nos dois locais (Figura 2), foram superiores às encontradas por Oliveira et al. (2002), 100 dias após a semeadura, e por Boer et al. (2007), no florescimento, que constataram, respectivamente, 24,8 e $17,3 \mathrm{~kg} \mathrm{ha}^{-1}$ de P, em 14.180 e $1.0801 \mathrm{~kg} \mathrm{ha}^{-1}$ de matéria seca de milheto comum e variedade ADR500, respectivamente. No entanto, as quantidades de Ca acumuladas no milheto (Figura) foram inferiores às encontradas por Oliveira et al. (2002) e por Boer et al. (2007), que registraram, respectivamente, 93,3 e 76,3 $\mathrm{kg} \mathrm{ha}^{-1}$ de Ca.

Em relação ao $\mathrm{K}$, o acúmulo desse nutriente, considerando-se as três diferentes quantidades de sementes do milheto, nos dois locais (Figura 2), foi inferior aos 416,9 kg ha-1 encontrados por Boer et al. (2007), com a variedade de milheto ADR500, e superior aos encontrados por Teixeira et al. (2003) e Oliveira et al. (2002), em milheto comum, os quais obtiveram, respectivamente, 50,9 e $20,8 \mathrm{~kg} \mathrm{ha}^{-1}$ de $\mathrm{K}$, com produção de 2.907 e $14.180 \mathrm{~kg} \mathrm{ha}^{-1}$ de matéria seca. Segundo Boer et al. (2007), o elevado acúmulo de K na variedade de milheto ADR500 deve-se ao fato de a 
Quadro 2. Teores médios de macronutrientes das plantas de cobertura e do pousio, no florescimento, nas duas localidades avaliadas, em 2009

\begin{tabular}{|c|c|c|c|c|c|c|c|}
\hline Cobertura & Quantidade de semente & $\mathbf{N}$ & $\mathbf{P}$ & $\mathbf{K}$ & $\mathrm{Ca}$ & Mg & $\mathrm{S}$ \\
\hline & \multirow[t]{2}{*}{$\mathrm{kg} \mathrm{ha}^{-1}$} & \multicolumn{6}{|c|}{$-\mathrm{g} \mathrm{kg}^{-1}$} \\
\hline & & \multicolumn{6}{|c|}{ Votuporanga (SP) } \\
\hline Sorgo & 6 & $23,22 \mathrm{abc}$ & $7,42 \mathrm{a}$ & 15,75 ef & $4,47 \mathrm{bc}$ & $3,58 \mathrm{ab}$ & $1,90 \mathrm{abcd}$ \\
\hline Sorgo & 7 & $22,30 \mathrm{abc}$ & $6,24 \mathrm{a}$ & $14,63 \mathrm{f}$ & $4,25 \mathrm{bc}$ & $3,14 \mathrm{ab}$ & $1,68 \mathrm{~d}$ \\
\hline Sorgo & 8 & $21,25 \mathrm{abc}$ & $5,83 \mathrm{ab}$ & $15,88 \mathrm{def}$ & $4,15 \mathrm{bc}$ & $3,00 \mathrm{ab}$ & $1,77 \mathrm{~cd}$ \\
\hline Milheto & 10 & $18,39 \mathrm{~cd}$ & $6,60 \mathrm{a}$ & 20,88 cde & $4,83 \mathrm{bc}$ & $3,14 a b$ & $2,56 \mathrm{abc}$ \\
\hline Milheto & 15 & $18,01 \mathrm{~cd}$ & $5,94 \mathrm{ab}$ & $22,63 \mathrm{c}$ & $4,77 \mathrm{bc}$ & $3,15 \mathrm{ab}$ & $2,59 \mathrm{abc}$ \\
\hline Milheto & 20 & $19,25 \mathrm{bc}$ & $5,67 \mathrm{ab}$ & $21,63 \mathrm{~cd}$ & $5,32 \mathrm{~b}$ & $3,32 \mathrm{ab}$ & $2,67 \mathrm{a}$ \\
\hline Capim-sudão & 12 & $19,34 \mathrm{bc}$ & $5,08 \mathrm{ab}$ & $13,38 \mathrm{f}$ & $4,26 \mathrm{bc}$ & $3,02 \mathrm{ab}$ & $1,56 \mathrm{~d}$ \\
\hline Capim-sudão & 15 & $21,67 \mathrm{abc}$ & $6,07 \mathrm{ab}$ & $12,25 \mathrm{f}$ & $3,95 \mathrm{c}$ & $2,76 a b$ & $1,54 \mathrm{~d}$ \\
\hline Capim-sudão & 18 & $18,45 \mathrm{~cd}$ & $5,77 \mathrm{ab}$ & $12,63 \mathrm{f}$ & $4,72 \mathrm{bc}$ & $2,78 \mathrm{ab}$ & $1,51 \mathrm{~d}$ \\
\hline Híbrido & 8 & $21,16 \mathrm{abc}$ & $6,46 \mathrm{a}$ & $12,25 \mathrm{f}$ & $3,84 \mathrm{c}$ & $2,84 \mathrm{ab}$ & $1,65 \mathrm{~d}$ \\
\hline Híbrido & 9 & $18,53 \mathrm{~cd}$ & $5,19 \mathrm{ab}$ & $14,88 \mathrm{f}$ & $4,13 \mathrm{bc}$ & $3,01 \mathrm{ab}$ & $1,54 \mathrm{~d}$ \\
\hline Híbrido & 10 & $13,02 \mathrm{~d}$ & $2,68 \mathrm{~b}$ & $13,50 \mathrm{f}$ & $3,51 \mathrm{c}$ & $2,70 \mathrm{~b}$ & $1,20 \mathrm{~d}$ \\
\hline U. ruziziensis & 8 & $26,30 \mathrm{a}$ & $4,65 \mathrm{ab}$ & $28,50 \mathrm{~b}$ & $4,17 \mathrm{bc}$ & $3,77 \mathrm{ab}$ & 1,98 abcd \\
\hline U. ruziziensis & 12 & $24,69 a b$ & $4,25 \mathrm{ab}$ & $26,00 \mathrm{bc}$ & $4,07 \mathrm{bc}$ & $3,55 \mathrm{ab}$ & $1,83 \mathrm{bcd}$ \\
\hline U. ruziziensis & 16 & $25,15 \mathrm{ab}$ & $4,10 \mathrm{ab}$ & $26,38 \mathrm{bc}$ & $4,11 \mathrm{bc}$ & $3,15 a b$ & $1,85 \mathrm{bcd}$ \\
\hline Controle & - & $26,07 \mathrm{a}$ & $5,89 \mathrm{ab}$ & $34,94 \mathrm{a}$ & $8,76 \mathrm{a}$ & $4,02 \mathrm{a}$ & $2,60 \mathrm{ab}$ \\
\hline DMS & & 6,00 & 3,512 & 5,80 & 1,34 & 1,29 & 0,82 \\
\hline \multirow[t]{2}{*}{ CV (\%) } & & 11,12 & 24,97 & 11,83 & 11,45 & 15,86 & 16,81 \\
\hline & & \multicolumn{6}{|c|}{ Selvíria (MS) } \\
\hline Sorgo & 6 & 22,68 abcd & $6,35 \mathrm{a}$ & 19,00 efghi & $2,99 \mathrm{c}$ & 4,59 abcd & $1,79 \mathrm{bc}$ \\
\hline Sorgo & 7 & 22,14 abcd & $6,16 \mathrm{abc}$ & 18,50 fghi & $3,04 \mathrm{c}$ & $4,02 \mathrm{~cd}$ & $1,79 \mathrm{bc}$ \\
\hline Sorgo & 8 & 20,79 abcde & $6,21 \mathrm{ab}$ & 20,00 defghi & $2,97 \mathrm{c}$ & 4,51 abcd & $1,73 \mathrm{bc}$ \\
\hline Milheto & 10 & 19,65 abcde & $4,73 \mathrm{abcd}$ & 23,17 bcdefg & $3,04 \mathrm{c}$ & $3,79 \mathrm{~d}$ & $2,70 \mathrm{ab}$ \\
\hline Milheto & 15 & 21,37 abcde & 5,11 abcd & 24,88 abcde & $3,20 \mathrm{bc}$ & $4,07 \mathrm{bcd}$ & $2,40 \mathrm{abc}$ \\
\hline Milheto & 20 & $17,45 \mathrm{de}$ & 4,69 abcd & 23,50 abcdef & $3,29 \mathrm{bc}$ & 4,17 abcd & $2,38 \mathrm{abc}$ \\
\hline Capim-sudão & 12 & $16,38 \mathrm{de}$ & $3,81 \mathrm{~cd}$ & 18,25 fghi & $3,28 \mathrm{bc}$ & $3,56 \mathrm{~d}$ & $1,60 \mathrm{c}$ \\
\hline Capim-sudão & 15 & $17,56 \mathrm{cde}$ & $3,85 \mathrm{~cd}$ & $15,75 \mathrm{hi}$ & $3,83 \mathrm{bc}$ & 4,94 abcd & $1,62 \mathrm{c}$ \\
\hline Capim-sudão & 18 & 19,65 abcde & 4,68 abcd & 20,38 cdefgh & $3,47 \mathrm{bc}$ & 4,70 abcd & $1,68 \mathrm{c}$ \\
\hline Híbrido & 8 & 18,53 bcde & 4,10 abcd & 17,17 ghi & $3,49 \mathrm{bc}$ & 4,66 abcd & $1,60 \mathrm{c}$ \\
\hline Híbrido & 9 & $17,11 \mathrm{de}$ & $3,71 \mathrm{~d}$ & $16,44 \mathrm{hi}$ & $3,24 \mathrm{bc}$ & 5,29 abcd & $1,47 \mathrm{c}$ \\
\hline Híbrido & 10 & $15,02 \mathrm{e}$ & $3,87 \mathrm{bcd}$ & $14,00 \mathrm{i}$ & $3,04 \mathrm{c}$ & $4,14 \mathrm{bcd}$ & $1,42 \mathrm{c}$ \\
\hline U. ruziziensis & 8 & $26,01 \mathrm{a}$ & 4,95 abcd & 26,00 abcd & $4,76 \mathrm{ab}$ & $5,96 \mathrm{a}$ & $2,83 \mathrm{a}$ \\
\hline U. ruziziensis & 12 & $24,29 \mathrm{abc}$ & $6,15 a b c$ & 29,75 a & $5,45 \mathrm{a}$ & $5,72 \mathrm{abc}$ & $3,17 \mathrm{a}$ \\
\hline U. ruziziensis & 16 & $24,59 \mathrm{ab}$ & 5,45 abcd & $26,50 \mathrm{abc}$ & $5,44 \mathrm{a}$ & $5,86 \mathrm{ab}$ & $2,93 \mathrm{a}$ \\
\hline Controle & - & $24,68 \mathrm{ab}$ & $6,45 \mathrm{a}$ & $28,92 \mathrm{ab}$ & $4,55 \mathrm{abc}$ & 5,11 abcd & $3,05 \mathrm{a}$ \\
\hline DMS & & 6,82 & 2,35 & 6,28 & 1,60 & 1,79 & 1,02 \\
\hline CV (\%) & & 12,98 & 18,30 & 11,45 & 16,91 & 14,90 & 18,61 \\
\hline
\end{tabular}

Médias seguidas de mesma letra não diferem entre si pelo teste de Tukey a $5 \%$.

cultivar utilizada ser resultante de um programa de melhoramento genético e possuir grande capacidade de produção de biomassa, ciclagem e acúmulo de nutrientes.

Quanto ao $\mathrm{Mg}$, o acúmulo desse nutriente nas três diferentes quantidades de sementes do milheto, nos dois locais (Figura 2), foi inferior ao obtido por Boer et al. (2007), que encontraram 39,8 $\mathrm{kg} \mathrm{ha}^{-1}$ de $\mathrm{Mg}$ em $10.801 \mathrm{~kg} \mathrm{ha}^{-1}$ de biomassa.

Os valores acumulados de $\mathrm{S}$, pelos três diferentes gastos de sementes do milheto nos dois locais (Figura 2), foram superiores aos registrados por Boer et al. (2007), 17,9 $\mathrm{kg} \mathrm{ha}^{-1}$, com $10.801 \mathrm{~kg} \mathrm{ha}^{-1}$ de biomassa seca de milheto. 
Quadro 3. Teores médios de fósforo, matéria orgânica (MO), pH, potássio e cálcio, magnésio, acidez potencial $(\mathrm{H}+\mathrm{Al})$, alumínio, enxofre e saturação por bases (V) no solo pós-milho, nas duas localidades avaliadas, em 2010

\begin{tabular}{|c|c|c|c|c|c|c|c|c|c|c|c|}
\hline Cobertura & Quantidade de semente & pH & $\mathbf{P}$ & MO & $\mathbf{K}$ & $\mathbf{C a}$ & Mg & $\mathrm{H}+\mathrm{Al}$ & $\mathrm{Al}^{(1)}$ & $\mathbf{S}^{(1)}$ & V \\
\hline & $\mathrm{kg} \mathrm{ha} \mathrm{h}^{-1}$ & \multicolumn{8}{|c|}{$\mathrm{mmol}_{\mathrm{c}} \mathrm{dm}^{-3}-$} & $\mathrm{ng} \mathrm{dm}^{-3}$ & $\%$ \\
\hline & & \multicolumn{10}{|c|}{ Votuporanga (SP) } \\
\hline Sorgo & 6 & 5,2 & 29 & 17 & $2,2 \mathrm{ab}$ & 15 & 6 & 16 & 0 & 5 & 59 \\
\hline Sorgo & 7 & 4,8 & 27 & 17 & $2,0 \mathrm{ab}$ & 14 & 6 & 18 & 2 & 6 & 54 \\
\hline Sorgo & 8 & 5,3 & 30 & 17 & $2,2 \mathrm{ab}$ & 14 & 6 & 17 & 1 & 5 & 57 \\
\hline Milheto & 10 & 5,3 & 34 & 17 & $2,4 \mathrm{ab}$ & 16 & 7 & 16 & 0 & 2 & 61 \\
\hline Milheto & 15 & 5,1 & 28 & 17 & $1,8 \mathrm{ab}$ & 16 & 7 & 17 & 1 & 5 & 59 \\
\hline Milheto & 20 & 5,3 & 34 & 17 & $2,4 \mathrm{ab}$ & 14 & 5 & 16 & 0 & 3 & 56 \\
\hline Capim-sudão & 12 & 5,3 & 28 & 17 & $2,2 \mathrm{ab}$ & 18 & 8 & 15 & 0 & 4 & 65 \\
\hline Capim-sudão & 15 & 5,1 & 35 & 17 & $2,1 \mathrm{ab}$ & 16 & 6 & 17 & 1 & 3 & 60 \\
\hline Capim-sudão & 18 & 5,3 & 29 & 17 & $2,0 \mathrm{ab}$ & 17 & 7 & 15 & 0 & 3 & 64 \\
\hline Híbrido & 8 & 5,1 & 24 & 17 & $1,8 \mathrm{ab}$ & 14 & 6 & 15 & 0 & 5 & 58 \\
\hline Híbrido & 9 & 5,1 & 28 & 17 & $1,5 \mathrm{~b}$ & 16 & 6 & 17 & 1 & 4 & 58 \\
\hline Híbrido & 10 & 5,1 & 20 & 16 & $2,0 \mathrm{ab}$ & 13 & 5 & 16 & 1 & 9 & 56 \\
\hline U. ruziziensis & 8 & 5,2 & 30 & 18 & $2,2 \mathrm{ab}$ & 16 & 6 & 16 & 0 & 2 & 60 \\
\hline U. ruziziensis & 12 & 5,2 & 25 & 17 & $2,3 \mathrm{ab}$ & 16 & 7 & 16 & 0 & 2 & 61 \\
\hline U. ruziziensis & 16 & 5,2 & 34 & 18 & $2,5 \mathrm{ab}$ & 17 & 7 & 17 & 0 & 2 & 61 \\
\hline Controle & & 5,2 & 26 & 17 & $2,7 \mathrm{a}$ & 14 & 6 & 16 & 0 & 4 & 59 \\
\hline DMS & & 0,6 & 16,6 & 1,6 & 1,1 & 6,4 & 3,1 & 4,2 & 0,7 & 1,8 & 14 \\
\hline \multirow[t]{2}{*}{ CV (\%) } & & 4,4 & 22,5 & 3,7 & 19,6 & 16,3 & 19 & 10,2 & 32,7 & 34,5 & 9,3 \\
\hline & & \multicolumn{10}{|c|}{ Selvíria (MS) } \\
\hline Sorgo & 6 & 5,3 & 25 & $23 \mathrm{a}$ & 1,3 & $35 \mathrm{ab}$ & 31 & $29 \mathrm{bc}$ & $3 \mathrm{~b}$ & - & $54 \mathrm{ab}$ \\
\hline Sorgo & 7 & 5,2 & 27 & $22 \mathrm{ab}$ & 0,9 & $52 \mathrm{a}$ & 34 & $32 \mathrm{abc}$ & $5 a b$ & - & $50 \mathrm{ab}$ \\
\hline Sorgo & 8 & 5,2 & 34 & $23 a b$ & 1,0 & $42 \mathrm{ab}$ & 33 & $32 \mathrm{abc}$ & $5 a b$ & - & $50 \mathrm{ab}$ \\
\hline Milheto & 10 & 4,2 & 32 & $23 \mathrm{a}$ & 1,3 & $7 \mathrm{ab}$ & 7 & $49 \mathrm{ab}$ & $8 \mathrm{ab}$ & - & $24 \mathrm{ab}$ \\
\hline Milheto & 15 & 4,2 & 23 & $23 \mathrm{ab}$ & 1,0 & $6 \mathrm{ab}$ & 6 & $44 \mathrm{abc}$ & $8 a b$ & - & $23 \mathrm{ab}$ \\
\hline Milheto & 20 & 4,4 & 22 & $22 \mathrm{ab}$ & 1,0 & $9 \mathrm{ab}$ & 8 & $41 \mathrm{abc}$ & $6 a b$ & - & $30 a b$ \\
\hline Capim-sudão & 12 & 5,2 & 31 & $23 \mathrm{ab}$ & 1,2 & $28 \mathrm{ab}$ & 25 & 33 abc & $5 a b$ & - & $49 \mathrm{ab}$ \\
\hline Capim-sudão & 15 & 5,1 & 34 & $23 \mathrm{a}$ & 0,8 & $28 \mathrm{ab}$ & 26 & $33 \mathrm{abc}$ & $6 \mathrm{ab}$ & - & $48 \mathrm{ab}$ \\
\hline Capim-sudão & 18 & 5,5 & 26 & $20 \mathrm{~b}$ & 1,3 & $29 \mathrm{ab}$ & 29 & $25 \mathrm{c}$ & $2 \mathrm{~b}$ & - & $59 \mathrm{a}$ \\
\hline Híbrido & 8 & 5,0 & 30 & $21 \mathrm{ab}$ & 0,9 & $17 \mathrm{ab}$ & 14 & $34 \mathrm{abc}$ & $5 a b$ & - & $47 \mathrm{ab}$ \\
\hline Híbrido & 9 & 4,9 & 46 & $22 \mathrm{ab}$ & 0,7 & $15 \mathrm{ab}$ & 11 & $37 \mathrm{abc}$ & $6 a b$ & - & $42 \mathrm{ab}$ \\
\hline Híbrido & 10 & 4,9 & 27 & $23 \mathrm{a}$ & 0,8 & $15 \mathrm{ab}$ & 11 & $35 \mathrm{abc}$ & $5 a b$ & - & $43 \mathrm{ab}$ \\
\hline U. ruziziensis & 8 & 4,5 & 23 & $22 \mathrm{ab}$ & 1,4 & $10 \mathrm{ab}$ & 9 & $41 \mathrm{abc}$ & $6 a b$ & - & $34 \mathrm{ab}$ \\
\hline U. ruziziensis & 12 & 4,3 & 21 & $22 \mathrm{ab}$ & 0,8 & $8 a b$ & 7 & $44 \mathrm{abc}$ & $8 \mathrm{ab}$ & - & $27 \mathrm{ab}$ \\
\hline U. ruziziensis & 16 & 4,3 & 26 & $23 \mathrm{ab}$ & 1,0 & $7 \mathrm{ab}$ & 7 & $47 \mathrm{ab}$ & $9 \mathrm{ab}$ & - & $25 \mathrm{ab}$ \\
\hline Controle & & 4,1 & 27 & $21 \mathrm{ab}$ & 1,3 & $4 \mathrm{~b}$ & 5 & $50 \mathrm{a}$ & $11 \mathrm{a}$ & - & $17 \mathrm{~b}$ \\
\hline DMS & & 1,5 & 29,8 & 2,8 & 0,7 & 3,9 & 3,2 & 20,7 & 7,7 & - & 39,8 \\
\hline CV (\%) & & 12,4 & 41 & 4,9 & 26,2 & 38,4 & 33,7 & 21,4 & 49,2 & - & 39,9 \\
\hline
\end{tabular}

(1) A análise estatística refere-se aos dados transformados em SQRT (x + 0,50). Médias seguidas de mesma letra não diferem entre si pelo teste de Tukey a $5 \%$.

\section{CONCLUSÕES}

1. O capim-sudão, com $18 \mathrm{~kg} \mathrm{ha}^{-1}$ de sementes, e o sorgo granífero, com $6 \mathrm{~kg} \mathrm{ha}^{-1}$ de sementes, podem contribuir para a melhoria da fertilidade do solo.
2. As diferentes quantidades de sementes utilizadas para cada planta de cobertura não influenciaram sua produtividade de matéria seca, mas sim na absorção de nitrogênio e no teor de matéria orgânica do solo. 


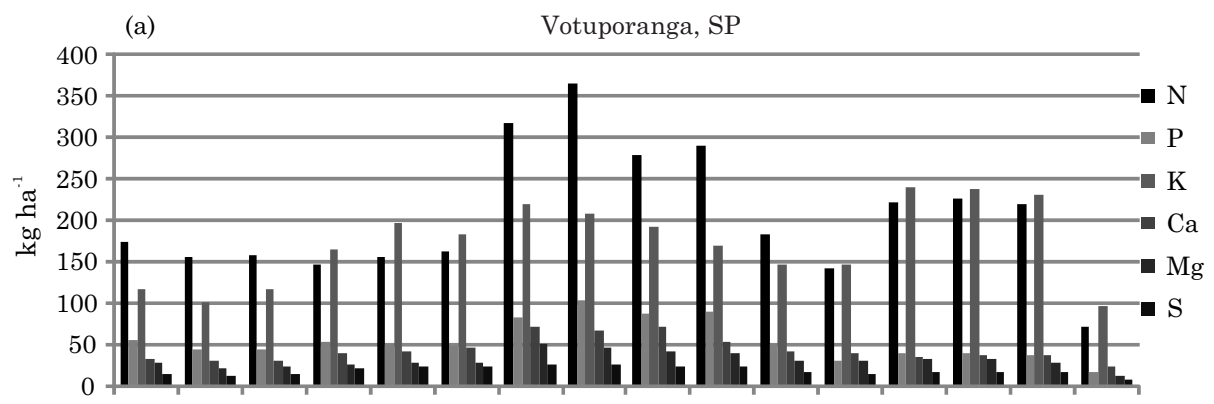

(b)

Selvíria, MS,

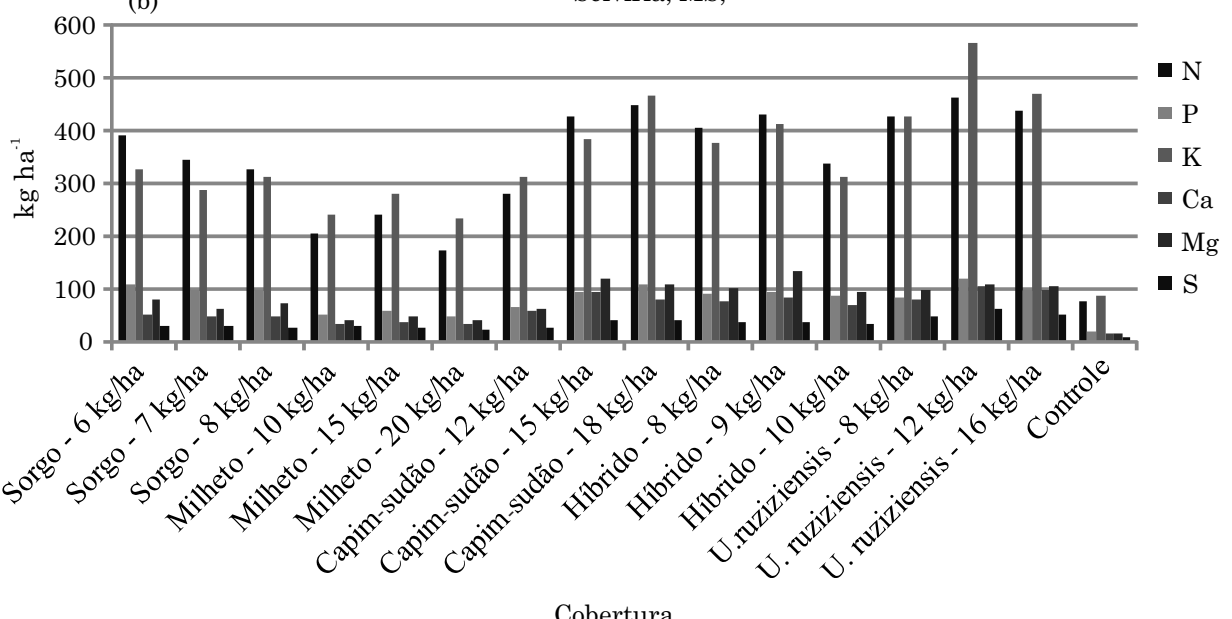

Figura 2. Teores médios de nitrogênio, fósforo, potássio, cálcio, magnésio e enxofre acumulados pelas plantas de cobertura, nas duas localidades avaliadas, em 2009.

\section{AGRADECIMENTOS}

À Fundação AGRISUS - Agricultura Sustentável, pelo apoio financeiro para instalação e condução da pesquisa científica. Ao Prof. Dr. Walter Veriano Valério Filho, do Departamento de Matemática da FEIS/ UNESP, pela colaboração nas análises estatísticas; e a todos os funcionários do Polo Regional de Desenvolvimento Tecnológico dos Agronegócios do Noroeste Paulista - APTA e da Fazenda de Ensino Pesquisa e Extensão da FEIS/UNESP, pelo apoio na instalação e condução dos campos experimentais.

\section{LITERATURA CITADA}

AITA, C.; BASSO, C.J.; CERETTA, C.A.; GONÇALVES, C.N. \& ROS, C.O. Plantas de cobertura do solo como fonte de nitrogênio ao milho. R. Bras. Ci. Solo, 25:157-165, 2001.

ALCÂNTARA, F.A.; FURTINI NETO, A.E.; PAULA, M.B.; MESQUITA, H.A. \& MUNIZ, J.A. Adubação verde na recuperação da fertilidade de um Latossolo VermelhoEscuro degradado. Pesq. Agropec. Bras., 35:277-288, 2000.

BAYER, C. \& MIELNICZUK, J. Características químicas do solo afetadas por métodos de preparo e sistemas de cultura. R. Bras. Ci. Solo, 21:105-112, 1997.
BOER, C.A.; ASSIS, R.L.; SILVA, G.P.; BRAZ, A.J.B.P.; BARROSO, A.L.L.; CARGNELUTTI FILHO, A. \& PIRES, F.R. Ciclagem de nutrientes por plantas de cobertura na entressafra em um solo de cerrado. Pesq. Agropec. Bras., 42:1269-1276, 2007.

CAIRES, E.F.; GARBUIO, F.J.; ALLEONI, F. \& CAMBRI, M.A. Calagem superficial e cobertura de aveia-preta antecedendo os cultivos de milho e soja em sistema de plantio direto. R. Bras. Ci. Solo, 30:87-98, 2006.

CORREIA, N.M. \& DURIGAN, J.C. Culturas de cobertura e sua influência na fertilidade do solo sob sistema de plantio direto. Biosci. J., 24:20-31, 2008.

CANTARELLA, H.; RAIJ, B.van \& SAWAZAKI, E. Sorgogranífero, forrageiro e vassoura. In: RAIJ, B.van.; CANTARELLA, H.; QUAGGIO, J.A. \& FURLANI, A.M.C., eds. Recomendações de adubação e calagem para o Estado de São Paulo. 2.ed. Campinas, IAC, 1997. p.66-67. (Boletim Técnico, 100)

CENTRO INTEGRADO DE INFORMAÇÕES AGROMETEOROLÓGICAS - CIIAGRO. Resenha: Votuporanga e Ilha Solteira no período de 01/03/2008 até 31/04/2010. São Paulo, 2012. Disponível em: <http:/ /www.ciiagro.sp.gov.br/ciiagroonline/Listagens/ Resenha/LResenhaLocal.asp>. Acesso em: 20 maio 2012 .

CHAVES, J.C.D. \& CALEGARI, A. Adubação verde e rotação de culturas. Inf. Agropec., 22:53-60, 2001. 
DEMATTÊ, J.L.I. Levantamento detalhado de solos do "Campus experimental de Ilha Solteira". Piracicaba, ESALQ/USP - Departamento de Solos, Geologia e Fertilidade, 1980. 44p.

DUDA, G.P.; GUERRA, J.G.M.; MONTEIRO, M.T.; DE-POLLI, H. \& TEIXEIRA, M.G. Perennial herbaceous legumes as live soil mulches and their effects on $\mathrm{C}, \mathrm{N}$ and $\mathrm{P}$ of the microbial biomass. Sci. Agríc., 60:139-147, 2003.

EMPRESA BRASILEIRA DE PESQUISA AGROPECUÁRIA EMBRAPA. Centro Nacional de Pesquisa de Solos. Sistema brasileiro de classificação de solos. Rio de Janeiro, 2006. 306p.

ESTAT - Sistema para análises estatísticas. (V.2.0), Jaboticabal, Polo Computacional/Departamento de Ciências Exatas/ UNESP-FCAV, Campus de Jaboticabal, 1997.

FABIAN, A.J. Plantas de cobertura: efeito nos atributos do solo e na produtividade de milho e soja em rotação. Jaboticabal, Faculdade de Ciências Agrárias e Veterinárias, Universidade Estadual Paulista, 2009. 83p. (Tese de Doutorado)

HERNANDEZ, F.B.T.; LEMOS FILHO, M.A.F. \& BUZETTI, S. Software HIDRISA e o balanço hídrico de Ilha Solteira. Ilha Solteira, UNESP/FEIS, 1995. 45p. (Área de Hidráulica e Irrigação. Série Irrigação, 1)

MASCARENHAS, H.A.A. \& TANAKA, R.T. Soja. In: RAIJ, B.van.; CANTARELLA, H.; QUAGGIO, J.A. \& FURLANI, A.M.C., eds. Recomendações de adubação e calagem para o Estado de São Paulo. 2.ed. Campinas, Instituto Agronômico de Campinas, 1997. p.202-203. (Boletim Técnico, 100)

OLIVEIRA, T.K.; CARVALHO, G.J. \& MORAES, R.N.S. Plantas de cobertura e seus efeitos sobre o feijoeiro em plantio direto. Pesq. Agropec. Bras., 37:1079-1087, 2002.

PRADO, H.; JORGE, J.A. \& MENK, J.R.F. Levantamento pedológico detalhado e caracterização físico-hídrica dos solos da Estação Experimental de Agronomia de Votuporanga (SP). Campinas, Instituto Agronômico de Campinas, 1999. 24p. (Boletim Científico, 42)

PRIMAVESI, O.; PRIMAVESI, A.C. \& ARMELIN, M.J.A Qualidade mineral e degradabilidade potencial de adubos verdes conduzidos sobre Latossolos, na região tropical de São Carlos, SP, Brasil. R. Agric., 77:89-102, 2002.

RAIJ, B.van. \& CANTARELLA, H. Milho para grãos e silagem. In: RAIJ, B. van.; CANTARELLA, H.; QUAGGIO, J.A. \& FURLANI, A.M.C., eds. Recomendações de adubação e calagem para o Estado de São Paulo. 2.ed. Campinas, Instituto Agronômico de Campinas, 1997. p.56-59. (Boletim Técnico, 100)
RAIJ, B. van. \& QUAGGIO, J. A. Métodos de análise de solo para fins de fertilidade. Campinas, Instituto Agronômico de Campinas, 1983. 31 p. (Boletim técnico, 81)

RAIJ, B.van.; ANDRADE, J.C.; CANTARELLA, H. \& QUAGGIO, J.A., eds. Análise química para avaliação da fertilidade do solo. Campinas, Instituto Agronômico de Campinas, 2001. 285p.

RHEINHEIMER, D.S.; KAMINSKI, J.; LUPATINI, G.C. \& SANTOS, E.J.S. Modificações em atributos químicos de solo arenoso sob sistema de plantio direto. R. Bras. Ci. Solo, 22:713-723, 1998

SANTOS, G.G.; SILVEIRA, P.M.; MARCHÃO, R.L.; PETTER, F.A. \& BECQUER, T. Atributos químicos e estabilidade de agregados sob diferentes culturas de cobertura em Latossolo do cerrado. R. Bras. Eng. Agríc. Amb., 16:1171$1178,2012$.

SILVA, E.C.; MURAOKA, T.; GUIMARÃES, G.L. \& BUZETTI, S. Acúmulo de nutrientes em plantas de cobertura e no milho cultivado em sucessão sob diferentes doses de nitrogênio em plantio direto. R. Bras. Milho Sorgo, 5:202217, 2006.

SOUZA, Z.M. \& ALVES, M.C. Propriedades físicas e teor de matéria orgânica em um Latossolo Vermelho de cerrado sob diferentes usos e manejos. Acta Sci. Agron., 25:27-34, 2003.

TEIXEIRA, I.R.; SOUZA, C.M.; BORÉM, A. \& SILVA, G.F. Variação dos valores de $\mathrm{pH}$ e dos teores de carbono orgânico, cobre, manganês, zinco e ferro em profundidade em Argissolo Vermelho-Amarelo, sob diferentes sistemas de preparo de solo. Bragantia, 62:119-126, 2003.

TORRES, J.L.R.; PEREIRA, M.G.; ANDRIOLI, I.; POLIDORO, J.C. \& FABIAN, A.J. Decomposição e liberação de nitrogênio de resíduos culturais de plantas de cobertura em um solo de cerrado. R. Bras. Ci. Solo, 29:609-618, 2005.

TORRES, J.L.R. \& PEREIRA, M.G. Dinâmica do potássio nos resíduos vegetais de plantas de cobertura no cerrado. $R$. Bras. Ci. Solo, 32:1609-1618, 2008.

TORRES, J.L.R.; PEREIRA, M.G. \& FABIAN, A.J. Produção de resíduo vegetal por plantas de cobertura e mineralização de seus resíduos em plantio direto. Pesq. Agropec. Bras., 43:421-428, 2008.

TRABUCO, M. Produção de milho em plantio direto após plantas de cobertura. Jaboticabal, Universidade Estadual Paulista, 2008. 54p. (Dissertação de Mestrado) 